\title{
Prevalence and reporting of near-point binocular convergence and acuity vision deficits in potential research participants
}

\author{
Patrick A. Ament, Darcy K. Robbins, Callie J. Brockman, \\ aND RaEanNa HaWkINS \\ University of Central Missouri, Warrensburg, Missouri \\ SUSAN LAKE \\ Eyecare Specialties, Warrensburg, Missouri
}

AND

M. Beth BAZIN

Vision Development Associates, Kansas City, Missouri

\begin{abstract}
Visual abilities at near-point distances of $\mathbf{2 0 0}$ self-reported normal vision college students were assessed. Results show that normal visual functioning with no deficits is the exception. The most common visual deficits observed involved binocular lateral posture and fusion convergence deficits. Binocular and monocular acuity deficits also had high prevalence rates, although not as prevalent as the binocular convergence deficits. In addition, 1,340 articles published in four major journals from the years 1997-2004 were examined to ascertain the extent to which authors report the visual capabilities of their participants. Reporting of research participant visual abilities by authors using visual stimuli in experiments appears to be lacking. The results are discussed in terms of the potential impact that visual deficits may have on results obtained in experiments in which visual stimuli are used and the importance of reporting the visual assessment tests and procedures used to assess the visual abilities of potential participants.
\end{abstract}

Numerous perceptual and cognitive experiments involve the presentation of visual stimuli within a set period of time. Often, the time available to process the stimulus may be quite brief, as in the case of divided visual field studies. However, it has previously been observed that typical research participants possess numerous visual deficits related to acuity, even though they believe their vision to be unaffected (Coren \& Porac, 1975). Although they did not report prevalence rates separately for far and near distances, Coren and Porac found that $13.5 \%$ of 111 volunteer participants with self-reported normal vision had standard Snellen acuity equivalents of 20/40 or below. They note that acuity of $20 / 40$ and below is the usually accepted legal definition of impaired vision. The results also revealed that $42 \%$ of the participants responded with an acuity score between $20 / 30$ and $20 / 40$. The present work presents prevalence data for near-point acuity deficits, as well as deficits related to binocular convergence functioning, in a population of college-aged participants who believed that they had normal or corrected-to-normal vision. Because this population is often used in psychological experiments and many experiments present visual stimuli at near-point distances, ascertaining both the acuity and the binocular convergence abilities of this group at near-point distances is of particular importance.

The prevalence of numerous types of visual deficits in the general population is well established. Widespread occurrence of refractive deficits even when corrective lenses are worn was observed by Roberts (1968). This study showed that $52 \%$ and $59 \%$ of the population had worse than 20/20 far and near vision, respectively. Even when tested with available lenses, $34 \%$ and $43 \%$ of the population still had impaired far and near vision, respectively. Roberts and Rowland (1978) observed that $28 \%$ of the population had impaired far vision even in the better eye when available corrective lenses were worn by the participant. A large study focusing on refractive errors conducted by the Rand Corporation (Rubenstein, Lohr, Brook, \& Goldberg, 1982) showed that $27 \%$ of their sample had far-point vision impairment, $7 \%$ had a near vision impairment, and $37 \%$ had both far and near vision impairments. Even when corrective lenses were worn, the prevalence of visual impairment was $45 \%$. Overall, the Rand study showed that $66 \%$ of their sample had some type of visual impairment. More pertinent to the interest in this study is the observation that $47 \%$ of randomly selected university 
students had a measurable myopia and $30 \%$ had hyperopia (Kinge, Midelfart, \& Jacobsen, 1998). This observation is especially important because in numerous experiments conducted by behavioral scientists, university students are used as the primary or sole participants.

Although assessment of acuity abilities has traditionally been of primary interest to researchers screening potential participants, binocular dysfunction deficits have been suggested to be the most common type of visual deficit (Cooper \& Duckman, 1978; Scheiman et al., 1996) and have been observed in various populations. For example, a prevalence rate of $21 \%$ has been observed in an urban optometry clinic (Hokoda, 1985), and $32.3 \%$ of a group of university students with no refractive errors demonstrated a binocular dysfunction of some type (Pocar \& MartinezPalomera, 1997). With regard to a pediatric group of 8- to 12-year-olds also with minimal refractive errors, randomly selected from two optometry clinics, $50 \%$ of a sample of 415 children demonstrated binocular dysfunction deficits (Rouse, Hyman, Hussein, Solan, \& the CIRS Group, 1998). It should be noted that prevalence rates for binocular dysfunction do differ somewhat in the available studies, most likely due to differences in assessment techniques and the comprehensiveness of the eye examination (Daum, 1988; Rouse, Borsting, Deland, \& the CIRS Group, 2002). Clearly, though, these studies suggest that binocular convergence deficits constitute a significant percentage of the visual deficits that may be present even in the absence of any significant symptoms or refractive problems.

The effect of visual deficits on various higher order cognitive processes has also been well studied, primarily from an applied educational perspective, as well as from a basic opthamological and optometric science perspective. $\mathrm{Nu}$ merous studies have shown for some time that children with identified visual disturbances, including binocular functioning deficits, also have deficits in reading (Flax, Mozlin, \& Solan, 1984; Garzia et al., 1989; Kulp \& Schmidt, 1996a, 1996b; Solan \& Ciner, 1989), attention (Borsting, Rouse, $\& \mathrm{Chu}, 2005$ ), and academic performance (Borsting et al., 2003; Kulp, 1999).

A preponderance of evidence has shown that significant visual impairment and deficits may indeed be present in numerous populations and that these deficits have a significant negative impact on numerous functions. In the present work, we expanded on Coren and Porac's (1975) study by assessing a significantly greater range of visual abilities, including far- and near-point binocular functioning, in college students with self-reported normal or corrected-to-normal vision. Such students form a population from which participants are commonly selected for participation in many different types of experiments in which visual stimuli are used.

In addition to presenting the prevalence rates of selected visual deficits, Coren and Porac (1975) also conducted a review of articles from the years 1972-1974 in four major journals that publish a wide range of studies in which visual stimuli are used: Perception \& Psychophysics, Vision Research, the American Journal of Psychology, and the Journal of Experimental Psychology. The studies that they reviewed involved a wide range of visual stimuli and presentation rates. They found that fully $71.6 \%$ of the articles did not specify the visual capabilities of the participants involved. In addition, $15.9 \%$ of the articles stated only that the participants had normal or corrected-to-normal vision, with no mention of the tests or procedures utilized in order to determine the visual capabilities of the participants. Only $3 \%$ of the articles actually outlined the vision tests and apparatuses used when the participants were prescreened visually. Given the high prevalence rates observed for numerous visual deficits even in those with avowedly normal vision, attention to adequate reporting of visual abilities and the assessments used clearly was lacking. In order to ascertain whether the situation had improved since 1972-1974, in the present work, we also examined all the articles that described human experiments in which visual stimuli were used for the years 1997-2004, in the same journals as those reviewed by Coren and Porac (1975), except for one.

\section{METHOD}

\section{Participants}

Two hundred volunteer college undergraduate students participated in the study (129 of them female, 71 male; mean age = 22.8 years, $S E=0.47$ ). All the participants self-reported that they had normal or corrected-to-normal vision. Volunteers may have received some type of course credit for their participation, and all were treated in accordance with the ethical principles of the American Psychological Association (2001).

\section{Materials}

Vision deficit prevalence data. A Keystone ophthalmic telebinocular $^{1}$ utilizing the Keystone Visual Skills Series tests was used in order to assess numerous visual abilities, including binocular convergence functioning and acuity at both far- and near-point distances. A brief description of the individual tests can be found in the Appendix.

With the vision assessment equipment and procedure used, binocular convergence functioning at near- and far-point distances was assessed by measuring the resting lateral posture of the eyes, as well as fusion ability. Binocular, as well as monocular, acuity was also assessed at near- and far-point distances. Near point and far point correspond to $16 \mathrm{in}$. and $20 \mathrm{ft}$, respectively. It is noted that near point is the approximate distance for reading, as well as the approximate distance at which visual stimuli are presented in numerous types of experiments. Lateral posture refers to the directions of the lines of sight for each eye at rest. Fusion refers to the level of binocular coordination that is present. Both types of deficits can be further categorized depending on whether they reflect underconvergence (exophoria) or overconvergence (esophoria). It is assumed that optimal visual processing of stimuli presented at both near- and far-point distances occurs only when normal lateral posture and fusion are present.

Vision ability reporting data. In order to determine the extent to which investigators report the visual abilities of their participants, 1,340 research reports were reviewed. They represent all the published articles from 1997 through 2004 in four major journals that typically present the results of experiments in which visual stimuli are used. The journals consisted of the Journal of Experimental Psychology: Learning, Memory, and Cognition, the Journal of Experimental Psychology: Perception and Performance, Perception \& Psychophysics, and the American Journal of Psychology. As close as possible, except for limitations due to availability and name changes or expansion, such as is the case with the Journal of Experimental Psychology, the journals were the same as those reviewed by Coren and Porac (1975), except for one. 


\section{Procedure}

Vision deficit prevalence data. After completing informed consent procedures, all the participants were given a comprehensive visual assessment with the Keystone telebinocular, using the Vision Skills Series tests. Some of the vision assessment data were collected in conjunction with other ongoing research projects. All assessments were carried out in a small testing room with only a trained examiner and the participant present. The lights in the room were extinguished, and a small table lamp was used to provide illumination to allow for scoring of the vision record sheet by the examiner. In addition, a small lamp that is integral to the Keystone telebinocular was turned on to provide illumination of the test targets. The participants were debriefed and excused after all testing had been completed.

Vision ability reporting data. The information obtained from the Method section of each article reviewed included the following: (1) whether the authors had mentioned the visual abilities of the participants, (2) whether the participants had self-reported their visual abilities, and (3) whether the authors had reported specific visual assessment tests and procedures that were used.

\section{RESULTS}

On the basis of other studies (Ament \& Bazin, 2001) and informal observations of the occurrence of near-point lateral posture and acuity deficits seen in other studies in our lab, binocular convergence and acuity functioning at near-point distances were of particular interest in the present study and will be reported in the present work.

\section{Vision Deficit Prevalence Data}

The results show that the most common type of visual deficit observed in the present study consisted of nearpoint binocular convergence dysfunction consisting of lateral posture and fusion deficits. With regard to lateral posture, $65 \%$ of the assessed individuals who believed their vision to be normal displayed this deficit and were unaware of it, with $40 \%$ exophoric and $25 \%$ esophoric. In terms of fusion, $23.5 \%$ exhibited this deficit, with $10.5 \%$ exophoric and $13.0 \%$ esophoric (see Table $1 \mathrm{~A}$ and Figure 1). It should be noted that numerous individuals with a near-point lateral posture deficit also had a near-point fusion deficit.

Acuity deficits at near-point distances were also relatively common, whether with binocular or monocular assessment. As can be seen in Table 1B and Figure 2, 24\% of the participants exhibited less than expected binocular usable vision $(<20 / 20$ Snellen equivalent). Similar deficit rates were observed when each eye was assessed independently. Of note are the rates for usable vision that were assessed at $60 \%$ or less for binocular vision, as well as for monocular vision for the right and left eyes individually. These rates are $4 \%, 7 \%$, and $13 \%$, respectively.

\section{Vision Ability Reporting Data}

Analysis revealed that the situation has not changed since Coren and Porac's (1975) study in terms of how investigators report the visual capabilities of research participants. As is shown in Table 2 and Figure 3, there were some differences between the journals in terms of whether the vision abilities of the participants were reported in any fashion, with the highest percentage at $49 \%$ and the lowest
Table 1A

Percentages (With Counts in Parentheses) of Near-Point Binocular Convergence Deficits of Participants

\begin{tabular}{lcc}
\hline & \multicolumn{2}{c}{ Type } \\
\cline { 2 - 3 } \multicolumn{1}{c}{ Deficit } & Lateral Posture & Fusion \\
\hline Exophoria (underconvergence) & $40.0(80)$ & $10.5(21)$ \\
Esophoria (overconvergence) & $25.0(50)$ & $13.0(26)$ \\
Orthophoria (expected) & $35.0(70)$ & $76.5(153)$ \\
\hline
\end{tabular}

at $20.4 \%$. It seems that even in the best case, fewer than $50 \%$ of the published studies in which visual stimuli were used reported any information relative to the visual capabilities of their participants. For those articles in which the visual abilities of the participants were mentioned, many (48.9\%-20.4\%) provided no additional details other than stating that participants had normal or corrected-to-normal vision or something similar. When the method used to determine the visual abilities of the participants was reported, self-report was the most common $(20.8 \%-9 \%)$. Very few of the articles $(8.3 \%-1 \%)$ reported the actual vision assessment test or technique used.

\section{DISCUSSION}

Researchers performing experiments in which visual stimuli have been used have traditionally been concerned only with acuity in their participants, whether or not visual abilities were actually tested. The present study shows that potential participants with self-reported normal vision do, in fact, have acuity deficits that may be of some concern. However, the most prevalent deficits involve near-point binocular convergence deficits. These deficits are most common at the viewing distances typically used in experiments and may affect the processing of all visual stimuli, particularly high-speed presentations typically used in tachistoscopic studies. Indeed, a study by Ament and Bazin (2001) tested the impact of near-point binocular lateral posture and fusion convergence deficits on brief visual stimulus processing and showed that these particular deficits had a significant negative impact on a simple letter identification task that involved only minimal cognitive demands.

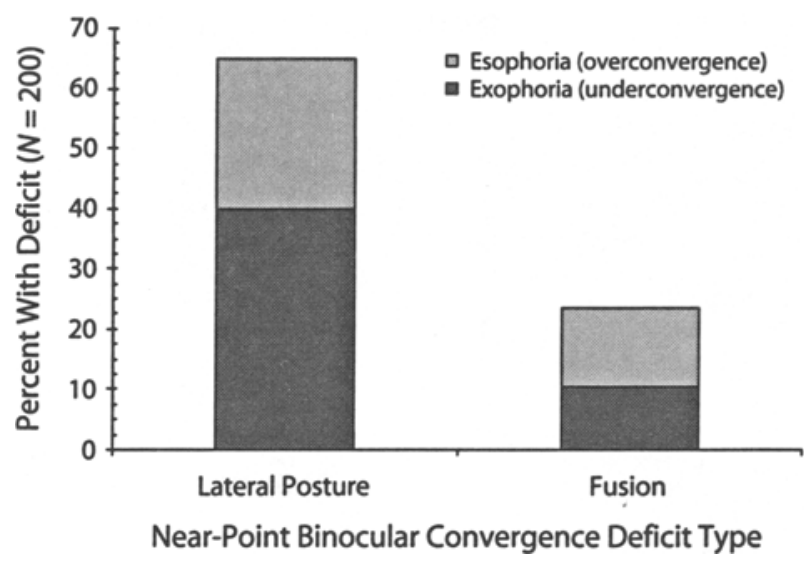

Figure 1. Percentage of individuals with near-point esophoric and exophoric binocular lateral posture or fusion deficits. 
Table 1B

Percentages (With Counts in Parentheses) for Binocular and Monocular Acuity Characteristics of Participants

\begin{tabular}{llrrrrr}
\hline \multirow{2}{*}{$\begin{array}{l}\text { Near-Point } \\
\text { Usable Vision }\end{array}$} & \multicolumn{1}{c}{$\begin{array}{c}\text { Snellen } \\
\text { Equivalent }\end{array}$} & \multicolumn{5}{c}{ Eye } \\
\cline { 2 - 6 } & \multicolumn{2}{c}{ Both } & \multicolumn{2}{c}{ Right } & \multicolumn{2}{c}{ Left } \\
\hline$<50 \%$ & $<20 / 40$ & 1.0 & $(2)$ & 4.5 & $(9)$ & 2.5 \\
$50 \%-60 \%$ & $20 / 33-20 / 40$ & 3.0 & $(6)$ & 2.5 & $(5)$ & $10.5(21)$ \\
$70 \%-90 \%$ & $20 / 22-20 / 28$ & $20.0(40)$ & $6.0(12)$ & $11.0(22)$ \\
$100 \%-105 \%$ & $20 / 20$ or better & $76.0(152)$ & $77.0(154)$ & $76.0(152)$ \\
\hline
\end{tabular}

Table 2

Percentage (With Count in Parentheses) of Articles That Made No Mention of Participant Visual Abilities, Those That Mentioned Only With No Details, Those That Used Participant Self-Report, and Those That Provided Information Regarding Specific Visual Tests and Procedures That Were Used

\begin{tabular}{lcccrc}
\hline \multicolumn{1}{c}{ Journal } & \multicolumn{1}{c}{$\begin{array}{c}\text { No } \\
\text { Mention }\end{array}$} & $\begin{array}{c}\text { No } \\
\text { Details }\end{array}$ & \multicolumn{1}{c}{$\begin{array}{c}\text { Self- } \\
\text { Report }\end{array}$} & $\begin{array}{c}\text { Vision } \\
\text { Test }\end{array}$ \\
\hline JEP: Human Penception and Performance & 452 & $26.3(119)$ & $48.9(221)$ & $20.8(94)$ & $4.0(18)$ \\
JEP: Learning, Memory, and Cognition & 289 & $61.2(177)$ & $28.7(83)$ & $9.0(26)$ & $1.0(3)$ \\
Perception \& Psychophysics & 545 & $22.7(124)$ & $49.0(267)$ & $20.0(109)$ & $8.3(45)$ \\
American Journal of Psychology & 54 & $61.1(33)$ & $20.4(11)$ & $14.8(8)$ & $3.7(2)$ \\
$\quad$ Total & 1,340 & & & & \\
\hline
\end{tabular}

Note-JEP, Journal of Experimental Psychology.

One of the implications of Ament and Bazin's (2001) study is the clear possibility that binocular convergence deficits may have the potential to add significant error variance to experimental paradigms in which visual stimuli are used, particularly those in which briefly presented visual stimuli are used. The effect of additional error variance, of course, would be to mask to some degree the effect of any experimental condition or treatment and increase the probability of a Type II error.

It could be assumed that since impaired near-point binocular functioning results in impaired performance in a simple letter identification task, performance may also suffer for more complex higher order cognitive processing. In addition to the negative impact that near-point binocular deficits may have on the processing of visual stimuli presented for very short durations, studies in which verbal stimuli that must be read by participants are presented at longer durations may also be of concern. As has previously been outlined, numerous studies have shown the negative impact of binocular deficits on reading and comprehension skills. To date, however, most of the available data pertains to populations younger than college-aged potential participants.

A number of caveats are in order. First, due to the high prevalence rates for the types of visual deficits observed in the present study, it may be unrealistic to pursue a sample with completely "normal" visual abilities. Second, virtually no studies have been conducted that have directly assessed the impact of undetected visual deficits with high prevalence rates in terms of actual increases in participant error variance in both between- and within-subjects designs. Studies intended to directly assess whether specific visual deficits significantly increase Type II error rates, as well as reduce observed effect sizes, are needed before any recommendation to more comprehensively assess the

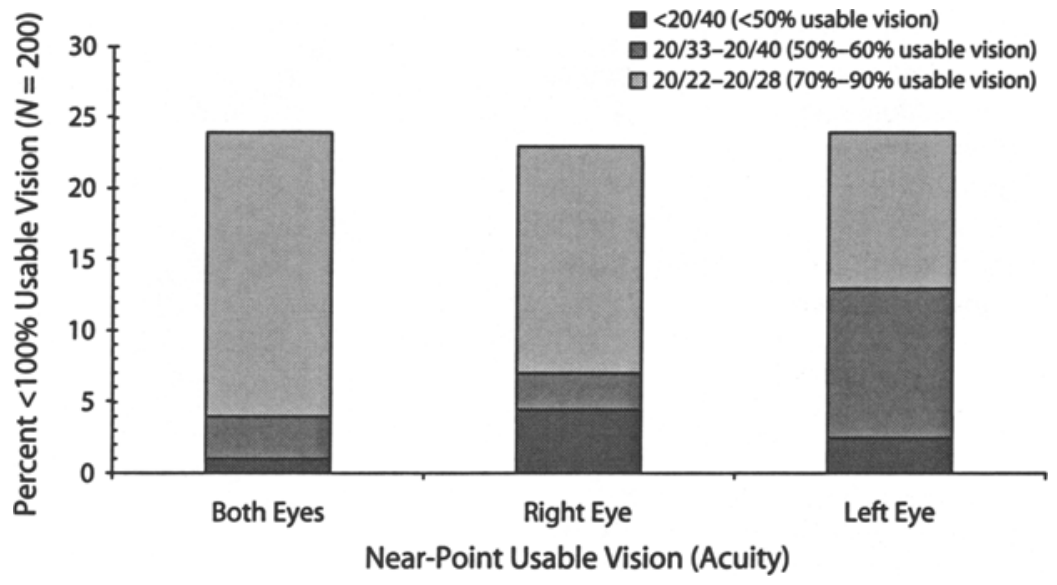

Figure 2. Percentage of individuals with very low, low, and moderate usable vision deficits. 


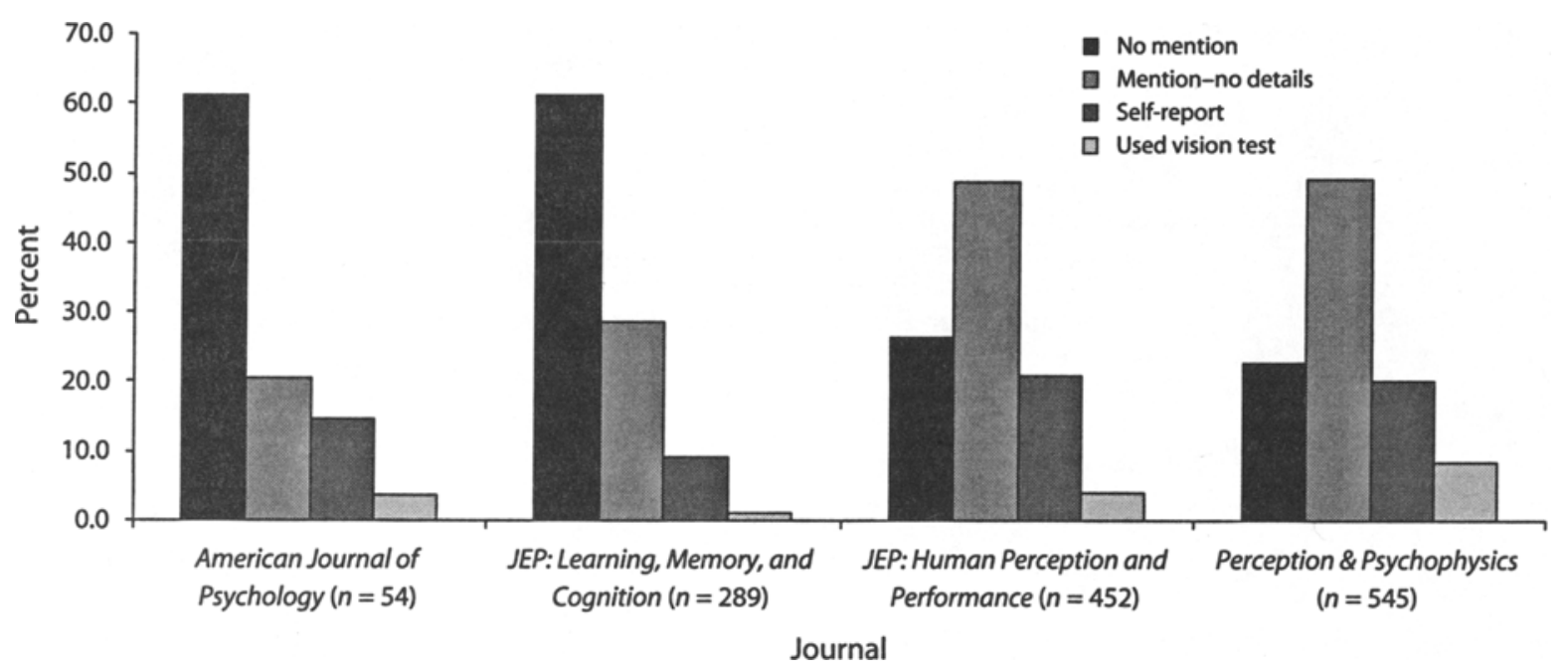

Figure 3. Percentage of journal articles that did not mention the visual abilities of participants, that only mentioned visual abilities without elaborating, that reported that visual abilities were determined through self-report, or that described specific vision assessment tests and procedures.

visual abilities of research participants in experiments in which visual stimuli are used can be proposed.

\section{AUTHOR NOTE}

Portions of the present study were presented at the 13th Annual Meeting of the Association for Psychological Science, Toronto. This work was supported by a technology grant from the University of Central Missouri. Grateful appreciation is extended to Melissa Watrous, Connie Ryland, Audrey Phelps, Lacey Huggins, Katie Simmonds, Courtney Hall, Tara Duckworth, Ben Reed, and Sheryl Cox for assistance in data collection and collation. This article is dedicated to the memory of Raeanna Hawkins. Correspondence doncerning this article should be addressed to P. A. Ament, Department of Psychology, University of Central Missouri, Warrensburg, MO 64093 (e-mail: ament@ucmo.edu).

\section{REFERENCES}

AMEnt, P. A., \& BAzIN, B. (2001). The effect of unreported visual deficits on the processing of brief visual stimuli. Journal of Behavioral Optometry, 11, 11-16.

AMERICAN PSYCHOLOGICAL ASSOCIATTON (2001). Ethical principles of psychologists and code of conduct. American Psychologist, 57, 1060-1073.

Borsting, E., Rouse, M. W., \& CHU, R. (2005). Measuring ADHD behaviors in children with symptomatic accommodative dysfunction or convergence insufficiency: A preliminary study. Journal of the American Optometric Association, 76, 588-592.

Borsting, E., Rouse, M. W., Deland, P. N., Hovett, S., Kimura, D., PARK, M., \& StePHENS, B. (2003). Association of symptoms and convergence and accommodative insufficiency in school-age children. Journal of the American Optometric Association, 74, 25-34.

COOPER, J., \& DuCKMaN, R. (1978). Convergence insufficiency: Incidence, diagnosis, and treatment. Journal of the American Optometric Association, 49, 673-680.

CoREN, S., \& PORAC, C. (1975). The myth of the normal eye: A methodological note. Bulletin of the Psychonomic Society, 5, 469-470.

DAUM, K. M. (1988). Characteristics of convergence insufficiency. American Journal of Optometric Physiology, 65, 426-438.

Flax, N., Mozlin, R., \& Solan, H. A. (1984). Discrediting the basis of the AAO policy: Learning disabilities, dyslexia, and vision. Journal of the American Optometric Association, 55, 399-403.

Garzia, R. P., Nicholson, S. B., Gaines, C. S., Murphy, M. A., KRAMER, A., \& PoTrs, J. (1989). Effects of nearpoint visual stress on psycholinguistic processing in reading. Journal of the American Optometric Association, 60, 38-44.

HoKODA, S. C. (1985). General binocular dysfunctions in an urban op- tometry clinic. Journal of the American Optometric Association, 56, 560-562.

Kinge, B., Midelfart, A., \& Jacobsen, G. (1998). Refractive errors among young adults and university students in Norway. Acta Ophthalmologica Scandinavica, 76, 692-695.

KULP, M. T. (1999). Relationship between visual motor integration skill and academic performance in kindergarten through third grade. $O p$ tometry \& Vision Science, 76, 159-163.

KULP, M. T., \& SCHMIDT, P. P. (1996a). Effect of oculomotor and other visual skills on reading performance: A literature review. Optometry \& Vision Science, 73, 283-292.

KULP, M. T., \& SCHMIDT, P. P. (1996b). Visual predictors of reading performance in kindergarten and first grade children. Optometry \& Vision Science, 73, 255-262.

Pocar, E., \& Martinez-Palomera, A. (1997). Prevalence of general binocular dysfunction in a population of university students. Optometry \& Vision Science, 74, 111-113.

ROBERTS, J. (1968). Monocular-binocular visual acuity of adults: United States, 1960-1962 (NCHS Pub. 30-11, PHS 1000). Washington, DC: U.S. Department of Health, Education, and Welfare.

ROBERTS, J., \& ROWLAND, M. (1978). Refraction status and motility defects of persons 4-74 years: United States, 1971-1972 (NCHS Pub. 206-11, PHS 78-1654). Washington, DC: U.S. Department of Health, Education, and Welfare.

Rouse, M. W., Borsting, E., Deland, P. N., \& THE CIRS Group (2002). Reliability of binocular vision measurements used in the classification of convergence insufficiency. Optometry \& Vision Science, 79, 254-264.

Rouse, M. W., Hyman, L., Hussein, M., Solan, H., \& the CIRS Group (1998). Frequency of convergence insufficiency in optometry clinic settings. Optometry \& Vision Science, 75, 88-96.

Rubenstein, R. S., LoHr, K. N., Brook, R. H., \& GoldberG, G. A. (1982). Conceptualization and measurement of physiologic health for adults: Vision impairments (Rand Health Insurance Study, Vol. 12, R-2262/12-HHS. Santa Monica, CA: Rand Corporation.

Scheman, M., Gallaway, M., Coulter, R., Reinstein, F., Ciner, E., Herzberg, C., \& Parisi, M. (1996). Prevalence of vision and ocular disease conditions in a clinical pediatric population. Journal of the American Optometric Association, 67, 193-202.

SOLAN, H. A., \& Ciner, E. B. (1989). Visual perception and learning: Issues and answers. Journal of the American Optometric Association, $60,457-460$.

\section{NOTE}

1. Keystone View, Nevada Capital Group Inc., 2200 Dickerson Road, Reno, NV 89503. 


\section{APPENDIX}

Keystone Visual Skills Series Tests

\section{Far-Point Tests}

1. Simultaneous Perception: A gross suppression test.

2. Hyperphoria: A test for vertical imbalance.

3. Lateral Phoria: A test of lateral posture and postural stability.

4. Binocular Coordination: A test of fusion facility.

4.5. Binocular Acuity: Usable vision under fusion.

5. Usable Vision-Right Eye: A test of monocular discrimination under fusion.

6. Usable Vision-Left Eye: Same as Test 5.

7. Stereopsis: A test for loss of depth awareness.

\section{Near-Point Tests}

10. Lateral Phoria: Same as Test 3.

11. Binocular Coordination: Same as Test 4.

12. Binocular Acuity: Same as Test 4.5.

13. Usable Vision-Right Eye: Same as Test 5 .

14. Usable Vision-Left Eye: Same as Test 5.

(Manuscript received February 26, 2007;

revision accepted for publication May 22, 2007.) 